\title{
Burkitt Lymphoma: Pathogenesis and Immune Evasion
}

\author{
Jason M. God and Azizul Haque \\ Department of Microbiology and Immunology, Charles Darby Children's Research Institute, Hollings Cancer Center, \\ Medical University of South Carolina, 173 Ashley Avenue, Charleston, SC 29425, USA
}

Correspondence should be addressed to Azizul Haque, haque@musc.edu

Received 21 June 2010; Accepted 2 September 2010

Academic Editor: Rob S. Pieters

Copyright ( $\odot 2010$ J. M. God and A. Haque. This is an open access article distributed under the Creative Commons Attribution License, which permits unrestricted use, distribution, and reproduction in any medium, provided the original work is properly cited.

B-cell lymphomas arise at distinct stages of cellular development and maturation, potentially influencing antigen (Ag) presentation and T-cell recognition. Burkitt lymphoma (BL) is a highly malignant B-cell tumor associated with Epstein-Barr Virus (EBV) infection. Although BL can be effectively treated in adults and children, leading to high survival rates, its ability to mask itself from the immune system makes BL an intriguing disease to study. In this paper, we will provide an overview of BL and its association with EBV and the $c-m y c$ oncogene. The contributions of EBV and $c-m y c$ to B-cell transformation, proliferation, or attenuation of cellular network and immune recognition or evasion will be summarized. We will also discuss the various pathways by which BL escapes immune detection by inhibiting both HLA class I- and II-mediated Ag presentation to T cells. Finally, we will provide an overview of recent developments suggesting the existence of BL-associated inhibitory molecules that may block HLA class II-mediated Ag presentation to CD4+ T cells, facilitating immune escape of BL.

\section{Introduction}

Burkitt Lymphoma (BL) is a high-grade B-cell malignancy occurring most frequently in children in areas with holoendemic and hyperendemic malaria, and with lesser frequency in all other parts of the world $[1,2]$. This aggressive neoplasm is classified as a Non-Hodgkin's Lymphoma (NHL) and has the fastest doubling time among human tumors [3]. BL is subdivided into three different categories based on epidemiological observations: endemic BL (eBL), sporadic BL (sBL), and HIV-associated BL. About 95\% of eBL cases are associated with Epstein-Barr Virus (EBV) and are commonly found in Equatorial Africa and Papua New Guinea where malarial diseases are highly prevalent. In contrast, only $5-15 \%$ of sBL and $40 \%$ of HIV-associated BL are EBV positive [4-6].

EBV is a member of the herpes family of doublestranded DNA viruses with an icosahedral-shaped capsid [7]. Worldwide more than $90 \%$ of all people become infected with EBV at some point during their lifetime $[4,8]$. Though most infected individuals remain healthy, EBV is capable of leading to pathologic conditions, being linked to a variety of human diseases and malignancies. EBV also has the potential to transform normal human B lymphocytes into continuously growing immortalized cells such as BL and Blymphoblastoid cells. It is present in approximately $50 \%$ of Hodgkin's Lymphoma (HL), a disease which accounts for $1 \%$ of all malignancies in the United States, and is found with varying frequency in NHL [9-11]. EBV is implicated in infectious mononucleosis, T-cell lymphoma, adult T-cell leukemia, Natural Killer cell (NK) leukemia, posttransplant lymphoproliferative disorder, nasopharyngeal carcinoma, and various other lymphoid and epithelial malignancies [1216]. In most individuals, infection of $B$ lymphocytes by EBV is followed by a cytotoxic CD8+ T cell (CTL) response that controls the spread of the virus. This response can be generated by latent viral proteins including EBNAs (EBV Nuclear Ags) and LMPs (Latent Membrane Proteins), but is dominantly targeted towards EBNA3; the LMPs also elicit a cytotoxic CD4+ $\mathrm{T}$ cell response to EBV-transformed Bcell lines [17]. $T$ cells also recognize several lytic cycle proteins, such as BZLF1, BMLF1, BMRF1, and BHRF1 [18]. In spite of this vigorous $\mathrm{CD} 8+\mathrm{T}$ cell response, a population of infected B cells escapes immune-mediated elimination. 
Immunodeficiencies resulting from certain genetic disorders, organ transplantation, or infectious diseases (e.g., AIDS, malaria) can lead to reactivation and outgrowth of these EBV-infected B cells [10]. EBV infection can also lead to the generation of a number of proteins (e.g., EBNA1, c$m y c)$ which are involved in decreasing immune recognition of malignant B cells. In the following sections, we will look further at the role of EBV as a possible causal agent of BL as well as its involvement in contributing to immune evasion.

The common characteristic of virtually all BL is translocation of the MYC proto-oncogene to an immunoglobulin (Ig) locus [19]. MYC encodes the $c-m y c$ transcription factor which was first discovered nearly thirty years ago as a cellular homologue of an avian retroviral oncogene [20]. Since that time, MYC has been recognized as one of the most commonly activated oncogenes in human cancers. It is estimated to play a role in $20 \%$ of all cancers, with potential involvement in 100,000 cancer deaths in the US each year [21-23]. $c-m y c$ is a transcription factor belonging to the class of basic helix/loop/helix/leucine zipper proteins and high-throughput screening has indicated that $15 \%$ of all known genes lie within its target gene network [23, 24]. Functions of genes in this network include the regulation of cell-cycle progression, proliferation, differentiation, and apoptosis [23, 25]. Under normal conditions, $c-m y c$ is activated in response to mitogenic factors and repressed upon exposure to antiproliferative signals. The involvement of $c$-myc in leading to development of BL, as well as its role in decreasing immunogenicity, will be addressed later in this paper.

\section{Burkitt Lymphoma}

2.1. Overview. Studies suggest that eBL and sBL differ in geographical distribution and degree of association with EBV. eBL occurs primarily in equatorial Africa and Papua New Guinea, and has a 95\% association with EBV. sBL, which accounts for $1 \%-2 \%$ of adult lymphomas and $30 \%-$ $50 \%$ of pediatric lymphomas in the United States (US) and Western Europe, occurs in all other parts of the world, but has only a $15 \%$ association with EBV $[4,5,26]$. Subtypes of BL also differ in clinical manifestation. Typically, eBL presents as tumors affecting the jaw and facial bones while sBL more commonly arises in the gut and upper respiratory tract, forming tumors in the Waldeyer ring [27, 28]. HIVassociated BL characteristically involves the lymph nodes and bone marrow [19]. While eBL primarily affects children 4$7 \mathrm{y}, \mathrm{sBL}$ is seen in both children and young adults, having a median age of $30 \mathrm{y}$ [3]. For all three types of BL, males are more commonly affected than females [3]. For the years 1973-2005, there were 3,058 cases of BL diagnosed in the US. Five-year mortality showed a positive correlation to age with pediatric cases having a $\sim 25 \%$ mortality, adult cases $50 \%$ and geriatric cases $70 \%$ [29].

A feature observed in nearly $100 \%$ of $\mathrm{BL}$ is a reciprocal chromosomal translocation involving the proto-oncogene MYC on chromosome 8 and one of the Ig gene heavy or light chain loci on chromosomes 14, 2, or 22 [19].
The translocation to an Ig locus leads to deregulation and constitutive expression of $c-m y c$, with an overall effect of uncontrolled proliferation as well as a reduced threshold for induction of apoptosis [24]. Characteristics of BL cells seem to point to a germinal center (GC) origin. BL cells phenotypically resemble centroblasts, expressing high levels of BCL-6 [30] and show signs of somatic hypermutation (SHM), a common characteristic of GC B cells [31, 32]. A final piece of evidence that indicates a GC origin stems from the MYC translocations: the chromosome breakpoints involved in these translocations suggest a mistake of classswitch recombination (CSR) or SHM, two processes that occur in GC B cells [33, 34]. MYC translocation is considered a hallmark for BL and its role in disease progression and immune evasion will be discussed in greater detail later in this paper.

EBV-positive BL cells express low levels of activation markers, adhesion molecules, and costimulatory molecules and they grow as single-cell suspensions, rather than in clumps typical of B-lymphoblastoid cells [35]. Unlike Blymphoblastoid cell lines (B-LCL), BL cells exhibit a deficiency in stimulation of CD8+ $\mathrm{T}$ cells via HLA class I molecules [36]. We have shown that BL cells express detectable levels of HLA class II, but fail to effectively stimulate CD4+ T cells [37]. HLA class II proteins on BL cells were capable of binding antigenic peptides but the class IIpeptide complexes were not functional (unpublished data). However, under acidic conditions $(\mathrm{pH}=5.5), \mathrm{BL}$ cells were capable of forming functional class II-peptide complexes that could stimulate $\mathrm{T}$ cells at neutral $\mathrm{pH}$. Acidic eluates obtained from BL cells diminished functional HLA class II Ag presentation by B-LCL and CD4+ T cell responses under physiological condition [37], suggesting that BL-associated inhibitory molecules (BLAIM) may perturb CD4+ T cell recognition of BL cells. It remains unclear how BLAIM could interact with class II and the T-cell receptor (TcR), disrupting HLA class II-restricted immune recognition of BL.

2.2. HIV and Malaria as Coinfections. Study suggests that the geographical distribution of eBL corresponds greatly to that of malarial diseases and that the prevention of malaria may lead to a decreased incidence of eBL [38]. For eBL, there is a strong association with endemic Plasmodium falciparum malaria. A study conducted in Malawi (which is endemic for both malaria and $\mathrm{BL}$ ) revealed that children expressing high levels of antibodies for both pathogens had 13 times the risk of developing eBL when compared to children with low antibody levels [38]. Additionally, children with malarial diseases living in areas endemic for both EBV and malaria were shown to have significantly higher levels of EBV antibodies than either their healthy counterparts or children living in areas of sBL [39-41]. In spite of their strong association, the relative functions of the malarial parasite and EBV in the development of BL remains elusive. It is generally believed that hyperstimulation of B cells and suppression of T-cell activity by malaria allow for reactivation of EBV in infected B cells, which consequently increase in numbers. Suppression of T-cell activity is suggested by the fact that children 5-9 years old living in areas holoendemic for 
malaria displayed inferior IFN- $\gamma$ responses when compared to children living in malaria variable regions. This age range coincides with the peak age incidence for eBL [42]. Chene et al. [43] have reported that increasing levels of malarial Ags become trapped in secondary lymphoid organs, leading to hyperactivation of the germinal centers and increased SHM. As MYC translocations take place in the germinal centers during SHM, it is plausible to imagine an increase in the number of translocations which could ultimately lead to the development of BL.

HIV represents another infection that may aggravate the pathogenesis of BL. Up to $20 \%$ of $\mathrm{HIV}$-associated NHL in the Western World are BL, and HIV-positive patients are believed to have a 200-1000-fold greater risk of developing BL than HIV-negative patients [26]. It is widely accepted that immunodeficiency resulting from HIV infection is responsible for reactivation of EBV in latently infected $\mathrm{B}$ cells and this ultimately progresses to BL [38]. Recent studies have shown that the priming of circulating EBV-specific $\mathrm{CD} 8+\mathrm{T}$ cells is dependent on CD4+ $\mathrm{T}$ cells $[10,44]$. In HIV-infected individuals the CD4+ T-cell count is greatly reduced, leading to diminished CD8+ T-cell activity which permits reactivation of EBV-infected B cells [10]. While HIV-associated BL can be treated with various short-term, aggressive chemotherapeutic regimens in conjunction with highly active antiretroviral therapy (HAART), toxicity and immunosupression pose a threat to the patients. The use of rituximab in immunocompromised patients is also a debated issue, suggesting the need for the development of less toxic and more specific immunotherapies.

2.3. Treatment of $B L$. The evolution of chemotherapeutic treatments for $\mathrm{BL}$, as well those currently in use, has been reviewed by Aldoss et al. [45] and should be considered in order to appreciate the need for improved therapies. While it is beyond the scope of this review to thoroughly describe these treatments, a few salient points can be addressed. Early treatments for BL sought to use chemotherapy regimens that were being used for other NHL. However, when used for $\mathrm{BL}$, they showed far inferior responses and cure rates, and these results were attributed to BL's rapid doubling time. To overcome this, intensive chemotherapy with short intervals between treatments was explored as an option. These regimens showed improved responses, but increased treatmentassociated toxicities. Additionally, adults (particularly the elderly) had inferior response rates and were less tolerant to the toxicities than children. Various chemotherapeutic treatment options currently exist for treatment of BL, but virtually all have the same shortcomings such as inferior responses and decreased tolerance to treatment-associated toxicities in adults. An additional confounding factor is coinfection with HIV, in which aggressive chemotherapy further aggravates their already immunodeficient state and leads to severe toxicities $[3,46-51]$.

Immunotherapeutic treatment of $\mathrm{BL}$ is found in the form of the anti-CD20 monoclonal antibody, rituximab, which induces cell death in B cells by cell-dependent cytotoxicity, antibody-dependent cell-mediated cytotoxicity, or complement activation. Rituximab used in conjunction with chemotherapy has led to increased response rates in $\mathrm{BL}$ patients [52]. However, toxicities from the chemotherapy are still an issue in many patients, and additional immunosuppression resulting from the use of rituximab is also a concern for HIV-infected BL patients. In a study by Oriol et al. [53], a clinical trial evaluated the use of chemoimmunotherapy (intensive chemotherapy with 8 doses of rituximab) in HIVinfected and HIV-negative adult BL patients. The complete remission rates for the 2 groups were very similar, but the HIV-infected patients experienced a higher incidence of severe mucositis and infections. More recently, the anti-CD22 monoclonal antibody, epratuzumab, has entered clinical trials and shows a synergistic effect when used concomitantly with rituximab [54]. Thus, chemotherapy and chemoimmunotherapy have proved themselves as invaluable tools in the treatment of BL. However, due to the inferior tolerance and responses observed in adults and HIV patients, there remains a need for more targeted and less toxic therapies for BL. Our study indicates that BLAIM impairs the HLA class II Ag presentation pathway. If this molecule can be identified and characterized, it may allow for the development of monoclonal antibodies which could have much more targeted effects than existing antibodies. This could also be combined with rituximab or epratuzumab to eliminate the need for toxic chemotherapies in some patients. In addition to the therapies discussed above for BL, adoptive transfer of EBV-specific T cells has shown some promise in treating hematopoietic stem cell transplant and solid organ transplant patients [55]. Any such therapy used for treatment of BL would have to address the low immunogenicity of EBNA1 as well as the decreased HLA class II response imparted by BLAIM that is implied by our research.

\section{Burkitt Lymphoma and Transformation of B Cells}

3.1. EBV and B-Cell Transformation. EBV is known to be associated with BL to varying degrees, but the exact role that it plays in the development of BL has remained elusive. It is known that EBV is capable of transforming B cells and this may play a role in the pathogenesis of BL. The entry of EBV into B cells involves at least five viral glycoproteins. EBV binding is partially mediated by the viral envelope protein gp350 which binds to complement receptor 2 (CR2) on B cells and tethers the virus to the $\mathrm{B}$ cell, allowing viral gp42 to bind to HLA class II proteins $[56,57]$. Upon binding of EBV to the $\mathrm{B}$ cell, gp42 triggers membrane fusion which is carried out by the viral proteins $\mathrm{gB}, \mathrm{gH}$, and $\mathrm{gL}[58,59]$.

Following infection, EBV produces an array of Ags including six EBNAs, early Ags, viral capsid Ag, EBV-induced membrane Ag and latent membrane proteins (LMPs). The six EBNA proteins have varying expression patterns which relate to different pathologic conditions. EBV has three transcriptionally distinct forms of latency, each with a different expression pattern for latent EBV-encoded genes [34]. Latency I, associated with BL, is characterized by expression of EBNA1 and small noncoding EBV RNAs (EBERs). Latency II, associated with HL, is characterized by 
expression of EBNA1, LMP1, LMP2, and EBERs. Latency III, observed in posttransplant lymphoproliferative disorders, includes expression of all EBNAs, EBERs, and LMPs [34, 60, 61].

As it pertains to transformation of $\mathrm{B}$ cells, it seems the EBV products of primary importance are EBNA1, EBNA2, EBNA3C, EBNA-LP, LMP1, and LMP2A [62]. EBNA2 is one of the first viral protein to be expressed following infection of $\mathrm{B}$ cells and its expression is required for transformation $[12,63]$. It works in concert with EBNA-LP to activate cyclin $D 2$, driving the $B$ cell from $G_{0}$ into $G_{1}$, and its inactivation results in cell-cycle arrest and entry into apoptosis [64, 65]. EBNA2's role in transformation is essential because it acts as a transactivator for all six EBNAs as well as the LMPs. EBNA2 also interacts with the cellular DNA-binding elements RBP$J \kappa$ and PU.1 to mediate the transcription of numerous cellular genes which contribute to transformation $[63,66]$. Comprehensive screening has identified 550 cellular genes that are either significantly induced or repressed by EBNA2, including MYC [67, 68].

Among the viral genes under transcriptional control of EBNA2 are the transmembrane proteins LMP1 and LMP2A. These proteins mimic normal B-cell molecules and deliver growth and survival signals commonly seen in B-LCL. LMP1 functions as a homologue of CD40 and signals through the tumor-necrosis-factor-receptor-associated factors (TRAFs) that result in activation of the transcription factor NF$\kappa \mathrm{B}$, leading to cell survival and growth [69-71]. LMP2A performs a similar function by mimicking the signaling of the B-cell receptor (BCR). Both LMP2A and the BCR signal through immunoreceptor tyrosine-based activation motifs and trigger the B-cell signaling pathway that leads to production of inositol trisphosphate $\left(\mathrm{IP}_{3}\right)$ and diacylglycerol (DAG), ultimately resulting in cell survival but not cell growth $[34,70]$. In addition, EBNA3C has a role in cell cycle progression through degradation of the tumor suppressor protein, $\mathrm{pRb}[72]$.

3.2. c-myc and B-Cell Transformation. The translocation of MYC to an Ig locus is considered a hallmark of BL. The most frequently observed translocations show a break in the long arm of chromosome 8 , adjacent to or within the MYC gene. $80 \%$ of all BL show a $\mathrm{t}(8: 14)$ translocation while the other observed translocations are $\mathrm{t}(8: 22)$ and $\mathrm{t}(8: 2)$ [24, 73]. MYC translocation requires activation-induced cytidine deaminase (AID), leading to the thinking that $\mathrm{BL}$ arises from germinal center B cells, as AID is highly expressed in the germinal center and plays a role in SHM and CSR $[24,74,75]$. Due to the ambiguous role of EBV in eBL and sBL, the breakpoints involved in MYC translocation have been analyzed and suggest that those in eBL are more closely associated with the joining region while those in $\mathrm{sBL}$ are more closely associated with switch regions [3, 76-78]. Regardless of the particular translocation involved or the location of the breakpoint, all MYC translocations in BL bring the gene under control of an Ig locus, resulting in its constitutive activation. Because the expression of many genes is controlled by $c-m y c$, the outcome of its constitutive expression is cell growth, uncontrolled proliferation, and a reduced apoptotic threshold [24]. Overexpression of $c$ $m y c$ contributes to proliferation by inducing the activity of cyclins, while at the same time repressing the activity of the cyclin inhibitor $\mathrm{p} 27$. The proapoptotic properties of $c$ $m y c$ involve both the extrinsic (through interactions with TRAIL) and intrinsic (through interactions with p53 and Bim) pathways [79]. When taken together, these properties explain the observation that $\mathrm{BL}$ cells have a high proliferative index while remaining susceptible to apoptosis [24, 80].

Even though translocation of MYC is generally considered a hallmark for BL and this characteristic has been uniformly observed across the different BL subtypes, $c$ $m y c$ does not act alone. Overexpression of $c-m y c$ drives cells into the cell cycle, but it also leads to apoptosis in the absence of apoptosis-inhibiting signals. These signals may be provided by other oncogenes, such as ras or bcl2 , or in the case of EBV-positive BL by EBNA1, which is antiapoptotic [81, 82]. Further, in order for $c-m y c$ to initiate its transcriptional activities, it must first form a heterodimer with the constitutively expressed $\max$ [82]. If the formation of $c-m y c / m a x$ heterodimers is prevented, cells do not undergo $c$-myc-induced transformation. Thus, while overexpression of $c-m y c$ is required for development of $\mathrm{BL}$, it works in concert with other proteins to exert its effects on the cell.

It should be noted that some studies have shown a very small number of $\mathrm{BL}$ cases do not show any MYC translocation, yet still overexpress $c$-myc. This has been demonstrated for $<10 \%$ of sBL and linked to miRNA deregulation [83]. In cases of $\mathrm{BL}$ that are negative for MYC translocations, downregulation of the miRNAs let-7c and miRNA-34b (which negatively regulate $c-m y c$ mRNA translation) has been observed and postulated to be the cause of $c$ - $m y c$ overexpression. In contrast, cases of BL with MYC translocations also show higher expression levels of these miRNAs. This gives two distinct mechanisms by which $\mathrm{BL}$ cells may come to overexpress $c$-myc: (i) the translocation of MYC to an Ig locus, and (ii) downregulation of miRNAs which regulate translation of $c-m y c$ mRNA [83].

\section{Burkitt Lymphoma and Immune Evasion}

4.1. EBNA1 in Immune Evasion of BL. The immune system is capable of generating both CD4+ and CD8+ T-cell responses to several latent and lytic phase EBV-associated Ags, such as LMP1, LMP2, EBNA2, and EBNA3. Unfortunately, BL cells generally express only the EBNA1 protein, which is poorly antigenic and has little to no HLA class I response. The mechanism by which EBNAl escapes HLA class I presentation involves the presence of an internal glycinealanine (gly-ala) repeat that has a dual role in this process (Table 1). First, the gly-ala repeat prevents the formation of a functional complex with the proteasome, thus blocking the protein degradation necessary for HLA class I loading and presentation to CD8+ T cells [84]. Secondly, the glyala repeat causes a decrease in the translation of the EBNA1 mRNA, reducing the production of antigenic peptides [85]. Because EBNA1 limits its presentation by HLA class I 
TABLE 1: Factors may contribute to the defects in immune recognition of BL cells.

\begin{tabular}{|c|c|c|}
\hline Factor & Cells Affected & Function(s)/defect(s) in Immune Evasion \\
\hline \multirow{3}{*}{ EBNA1 } & $>90 \% \mathrm{eBL}$ & Negative regulation of own mRNA translation [64] \\
\hline & $5-10 \% \mathrm{sBL}$ & Internal gly-ala repeat blocks proteasomal degradation and consequent \\
\hline & 40\% HIV associated BL & HLA class I presentation [63] \\
\hline \multirow{5}{*}{ C-myc } & \multirow{5}{*}{ All BL } & Downregulation of HLA class I [30] \\
\hline & & Antagonism of NF- $\kappa$ B pathway \\
\hline & & Negative regulation of STAT1 signaling \\
\hline & & Impairment of interferon response [59] \\
\hline & & $\begin{array}{l}\text { Downregulation of accessory molecules important in immune response: } \\
\text { LFA-1, LFA-3, ICAM-1, and TAP [86-90] }\end{array}$ \\
\hline \multirow{2}{*}{ HLA class I } & \multirow{2}{*}{ All BL } & Down-regulated in BL $[71-74]$ \\
\hline & & Downregulation of CD80/86 in BL decreases HLA class I signaling \\
\hline \multirow{5}{*}{ HLA class II } & \multirow{5}{*}{ All BL } & Downregulation of CD80/86 in BL decreases HLA class II signaling \\
\hline & & Upregulation of HLA-DO causes decrease in formation of class \\
\hline & & II/peptide complexes $[91,92]$ \\
\hline & & BLAIM may impair functional Ag \\
\hline & & presentation by HLA class II (unpublished data). \\
\hline
\end{tabular}

molecules, the $\mathrm{CD} 8+\mathrm{T}$ cell response to $\mathrm{BL}$ is largely diminished.

While EBNA1 limits its presentation via the HLA class I pathway, alternative methods of Ag presentation may allow for EBNA1 epitopes to be displayed by HLA class II proteins. Studies conducted in the lab of Christian Munz reveal that EBV-seropositive adults virtually always express EBNA1-specific CD4+ T cells [93, 94]. Further, Leung et al. [95] have demonstrated that autophagy may play a key role in the presentation of EBNA1 epitopes by HLA class II, which is normally thought of in the context of presenting extracellular Ags. In this study they demonstrated that removal of a nuclear location sequence (NLS) from EBNA1 resulted in HLA class II presentation of EBNA1 epitopes on the surface of B-LCL $[95,96]$. Furthermore, the resulting Ag presentation was sensitive to treatment with 3-methyladenine, an inhibitor of autophagy. While these results certainly shed valuable light on the role of CD4+ $\mathrm{T}$ cells in recognizing the EBNA1 Ag and open the door to possible therapies for certain EBV-related disorders, the implications for BL may be more limited. Our recent study has also shown that BL cells are deficient in their ability to functionally present Ags via the HLA class II pathway. Thus, understanding the mechanisms by which BL cells escape immune recognition, may open new avenues for devising novel immunotherapies against malignant B cells.

4.2. $c$-myc in Immune Evasion of BL. The picture described above for EBNA1 is somewhat clouded with the realization that EBNA1 in B-LCL can be recognized by CD8+ T cells, implying that EBNA1 is not the sole player leading to immune evasion by BL, and other factors could be involved $[91,92]$. EBNA1 is generally the only EBV Ag produced in EBV-positive BL, but atypical cases of BL do exist in which other EBV Ags are synthesized. The immune response to these tumors was addressed by Kelly et al. [97] in a study where 10 cell lines were established from confirmed eBL tumors. Screening of the cell lines revealed 3 which expressed EBNA1, -3A, -3B, 3C, and truncated LMP. As previously discussed, the EBNA3 family is highly immunogenic and a better target for inducing CD8+ T-cell responses. Yet, even in these atypical BL tumors which expressed the EBNA3 family, optimum CD8+ T cell activation was not observed.

These puzzling observations can be partially explained by $c$-myc's activity in reducing the immunogenicity of BL. It is well established that cytotoxic CD8+ T cells do not efficiently recognize $\mathrm{BL}$ cells (whether positive or negative for $\mathrm{EBV}$ ) and are thus incapable of mounting an immune response [35]. $c-m y c$ expression in some tumors is inversely correlated with expression of HLA class I, and this may also be true for $\mathrm{BL}$ (Table 1). In this study, though the mechanisms responsible were not elucidated, an immunogenic B-LCL that is normally recognized by cytotoxic T cells was rendered nonimmunogenic when $c$-myc was overexpressed [35]. An additional piece of the puzzle in determining how $c$-myc exerts its immune inhibitory activities was provided when Schlee et al. [86] demonstrated that $c$-myc overexpression alters mRNA profiles in conditional B-cell lymphoma lines via the $\mathrm{NF} \kappa \mathrm{B}$ activation pathway (Table 1 ).

Earlier studies had shown that overexpression of $c$ myc led to decreased expression of accessory molecules important in the immune response, including LFA-1, LFA3, ICAM-1, and TAP [87-90] (Table 1). Conversely, Staege et al. [35] found that inactivation of $c-m y c$ results in restored expression levels of these accessory molecules and $\mathrm{Ag}$ presentation. Further insight into $c$-myc's involvement in immune evasion is gleaned from studies showing that another hallmark feature of $\mathrm{BL}$ is little to no expression of NF- $\kappa \mathrm{B}[90,98,99]$. It was eventually determined that low $\mathrm{NF}-\kappa \mathrm{B}$ was responsible for the decreased expression of the accessory molecules observed in conditions of $c$ $m y c$ overexpression. In $\mathrm{BL}, \mathrm{NF}-\kappa \mathrm{B}$ regulates proapoptotic 

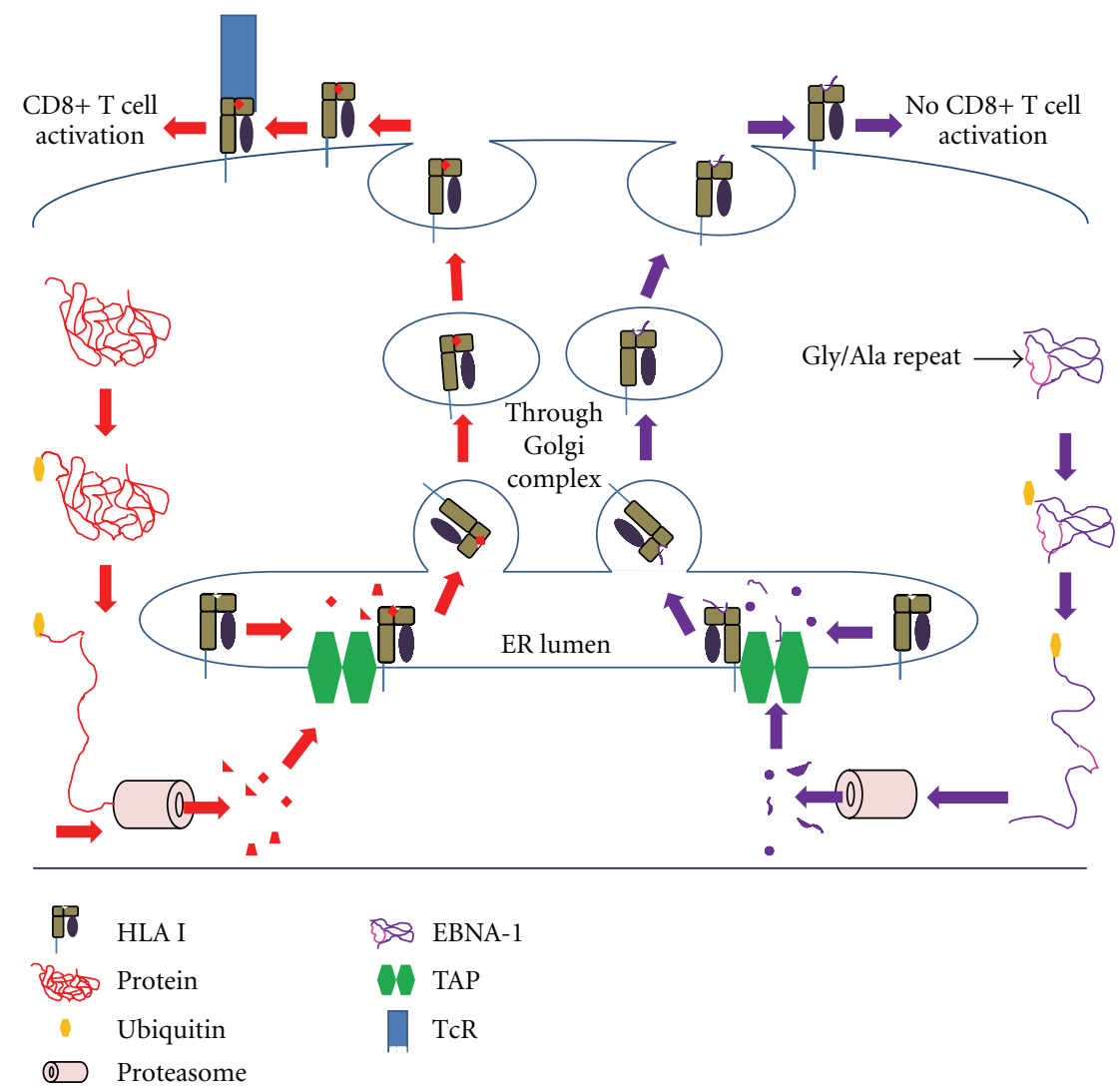

FIGURE 1: Defects in HLA class I antigen processing and presentation associated with BL. Cytosolic proteins are ubiquitinated, marking them for proteasomal degradation. Peptides generated from proteasomal degradation are then transported into the endoplasmic reticulum (ER) lumen by TAP (transporter associated with Ag presentation) and loaded onto HLA class I proteins. These class I peptide complexes are transported through the Golgi network to the cell surface for presentation to CD8+ T cells. The EBV EBNA1 protein contains a Gly/Ala repeat that impairs its proteasomal processing, resulting in the generation of peptides that are not readily accessible to class I molecules. Thus, peptides generated from EBNA1 proteins are unable to activate CD8+ T cells in the context of HLA class I molecules.

genes and restoration of its expression results in increased expression of Fas nd eventual cell death [90].

In addition to the impaired $\mathrm{NF} \kappa \mathrm{B}$ response, Schlee et al. [86] also found that genes involved in interferon (IFN) responses were down-regulated in BL when compared to B-LCL. These genes included STAT1 and STAT2 and a similar pattern was observed for genes connected to B-cell receptor signaling. This group also showed a sharp decrease in STAT1 protein and RNA expression in BL cells relative to B-LCL. The negative regulation of STAT1 by $c$-myc occurred directly, through blocking STAT1 expression, and indirectly by suppressing IFN induction. Thus, the overexpression of c-myc appears capable of decreasing the immunogenicity of both EBV-negative and EBV-positive BL by altering genes in the NF- $\kappa \mathrm{B}$ pathway. In EBV-positive BL cells, these activities would augment the poor antigenic property of EBNA1, facilitating immune evasion.

4.3. Evasion of HLA Class I Presentation. HLA class I molecules are expressed on every nucleated cell of the body and are involved in $\mathrm{Ag}$ presentation of cytosolic peptides to $\mathrm{CD} 8+\mathrm{T}$ cells $[100,101]$. As proteins are produced in the cytosol, they may become ubiquitinated, marking them for degradation in the proteasome (Figure 1). Peptides resulting from proteasomal degradation are transported into the lumen of the endoplasmic reticulum (ER) via the transporter associated with Ag presentation (TAP). In the ER lumen, HLA class I molecules can bind peptides approximately 810 amino acids long. Peptide-HLA class I complexes are then transported to the cell membrane for presentation to CTL (Figure 1). If the peptide is recognized by a CTL as being non-self, the CTL may induce apoptosis in the target cell through the perforin/granzyme pathway. Viral proteins are synthesized in the cytosol and are subjected to the same proteasomal degradation and HLA class I presentation for cellular protein as shown in Figure 1. This process is essential to the immune system's ability to monitor for viral infections and transformed cells and to mount an appropriate response. Indeed, the importance of this pathway is revealed by the strategy of HLA class I downregulation employed by many viruses and transformed cells to reduce their immunogenicity.

Although the pathway described above is the primary mechanism by which cells present endogenous $\mathrm{Ag}$ in the context of HLA class I, there are two alternative strategies that allow cells to present exogenous Ags via HLA class 


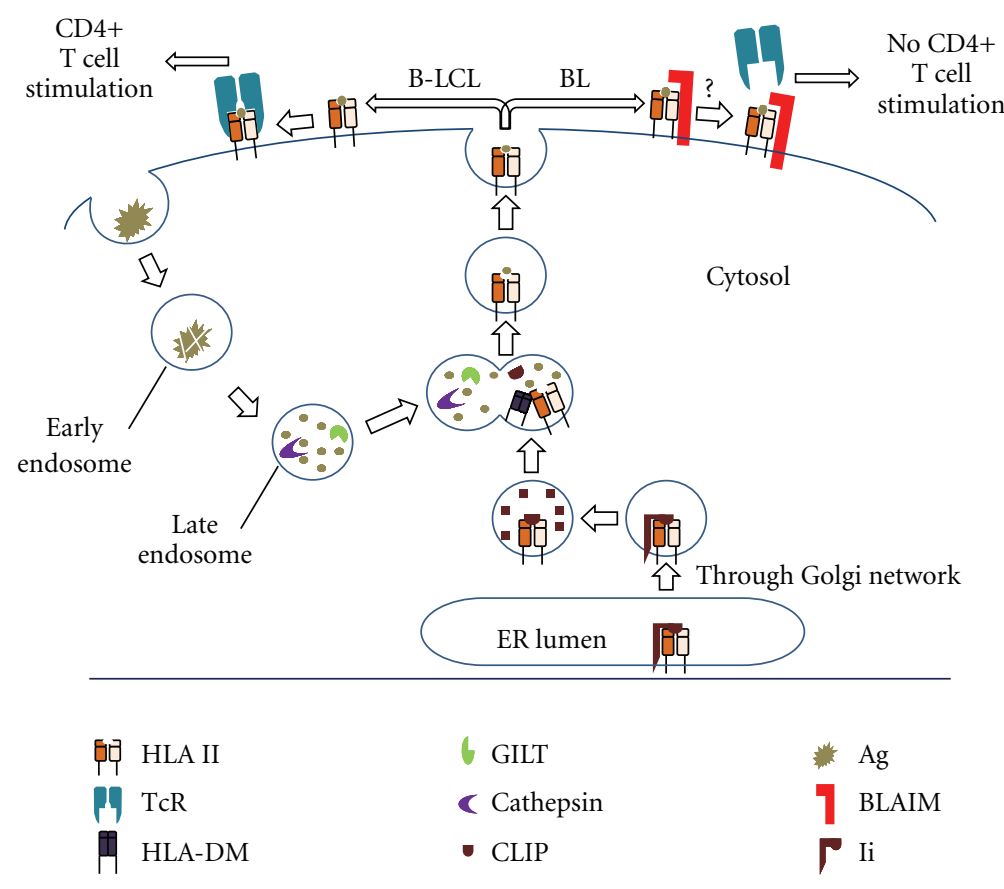

FIGURE 2: Defects in HLA class II antigen processing and presentation associated with BL. Extracellular Ags are endocytosed and degraded in increasingly acidified endolysosomal compartments. GILT helps in Ag/peptide processing by reducing disulfide bonds in the acidic environment. These peptides are further processed by acidic cathepsins for loading onto HLA class II proteins. HLA class II is synthesized in the ER lumen and forms a complex with Ii that is transported through the trans-Golgi network for processing by cathepsins in the endolysosomal compartments. Here Ii is degraded, leaving a fragment, CLIP, in the class II binding groove. HLA-DM mediates the release of CLIP and the loading of appropriate peptides onto HLA class II molecules. These complexes are then transported to the cell surface for presentation to CD4+ T cells. BL-associated inhibitory molecules (BLAIM) may interfere with functional class II presentation that perturbs $\mathrm{CD} 4+\mathrm{T}$ cell recognition of $\mathrm{BL}$.

I molecules. First, HLA class I molecules may bind short exogenous peptides for presentation to CTL [102]. Studies have demonstrated that some exogenous Ags can be directly delivered to the ER and that these Ags can be presented by HLA class I molecules [103, 104]. In spite of these mechanisms by which Ag may be presented by HLA class I, BL cells are not effectively controlled by CTL $[84,105]$. EBNA1, the sole EBV Ag expressed in EBV-positive BL, uses an internal gly-ala repeat to prevent its optimum presentation by HLA class I and largely escapes CTL detection (Figure 1).

A more general approach is also utilized by BL cells to avoid detection by CTL, and this involves the downregulation of HLA class I protein expression (Table 1). This is a common strategy that is widely observed in various virus-infected and transformed cells. In one study, BL lines derived from five HLA-A11-positive donors (both EBV positive and negative) were shown to have decreased expression levels of HLAA11 and were resistant to lysis by HLA-A11-restricted CTLs generated by stimulation with autologous B-LCL [106]. Other groups have investigated this aspect of BL immune evasion and reported similar observations, with HLA-A11 being the most commonly reported down-regulated form of HLA class I molecules [107, 108]. Based on the observations that a CTL response is capable of controlling outgrowth of B-LCL but is ineffective against EBV-positive BL cells, Jilg et al. [109] found that B-LCL expressed considerably higher levels of HLA class I molecules than those of BL. By preventing HLA class I presentation of the lone EBV $\mathrm{Ag}$ expressed in BL and by down-regulating HLA class I expression, BL minimizes detection by CTL and thus escapes a major portion of the immune response to both EBVpositive and EBV-negative BL. With CTL detection being largely avoided, the job of immune detection is left up to HLA class II-mediated Ag presentation.

4.4. Evasion of HLA Class II Presentation. While the HLA class I-mediated immune response to BL has been very well studied, the HLA class II-mediated response has not received nearly as much attention. BL cells express HLA class II molecules but their role in optimum Ag presentation and CD4+ T-cell stimulation remains unclear. HLA class II proteins are constitutively expressed by professional $\mathrm{Ag}$ presenting cells (APCs), such as macrophages, dendritic cells, and B cells $[110,111]$. Unlike the HLA class I binding pocket, the ends of the class II peptide-binding groove are open, thus allowing the bound peptides to extend from the ends of the groove, accommodating larger peptides of approximately 12-25 amino acids in length [112-114]. Additionally, HLA class I primarily presents endogenous Ags while HLA class II presents exogenous Ags including tumor and viral Ags. Although the emphasis has been given to the generation of CTL responses, these efforts have only led to short and 


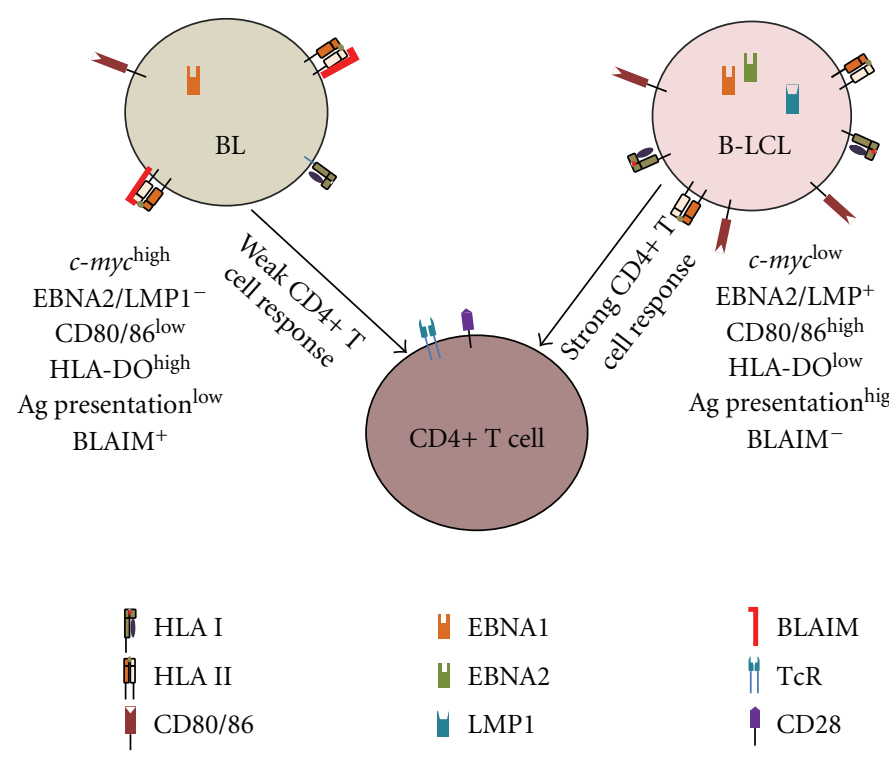

FIGURE 3: Comparison of BL and B-LCL highlighting the protein expression pattern of immune components that affects their abilities to stimulate CD4+ T cells. BL cells normally express EBNA1, but not EBNA2 and LMP1. When compared to B-LCL, BL cells express higher levels c-myc, HLA-DO and BLAIM and lower levels of costimulatory molecules (CD80/86) that differentially regulate Ag processing and presentation, resulting in poor $\mathrm{CD} 4+\mathrm{T}$ cell recognition of $\mathrm{BL}$.

weak responses in vaccinated patients. Increasing evidence suggests that the induction of optimal antitumor immunity requires both $\mathrm{CD} 4+$ and $\mathrm{CD} 8+\mathrm{T}$ cells specific for tumorassociated Ags $[115,116]$.

Numerous differences exist between HLA class I and class II synthesis and $\mathrm{Ag}$ processing, and these differences partially reflect the nature of the Ags bound by each class. HLA class II molecules are composed of alpha $(\alpha)$ and beta $(\beta)$ chains which are assembled in the ER and associated with the invariant chain (Ii) [112-114]. Ii aids in transporting class II molecules to the endolysosomal compartments, where Ii is sequentially degraded by cathepsins, leaving class IIassociated invariant-chain peptide (CLIP) on the class II binding groove $[110,113]$. Ags/Peptides are also processed in the endolysosomal compartments by acidic cathepsins for class II loading and presentation to $\mathrm{T}$ cells [117]. Some proteins, however, are not easily unfolded for further processing by endolysosomal cathepsins. We have shown that the expression of Gamma-IFN-inducible Lysosomal Thiol reductase (GILT) is essential for the proper processing of disulfide containing Ags and peptides inside the cells [118120]. GILT reduces disulfide bonds, allowing proteins to be unfolded and then processed by acidic proteases [121]. Removal of CLIP and formation of stable class II-peptide complexes is mediated by a nonclassical class II protein, HLA-DM $[122,123]$. Once peptide is bound to a class II protein, the HLA class II-peptide complex is transported to the cell surface for presentation to CD4+ T cells (Figure 2).

BL cells express lower levels of costimulatory molecules (e.g., CD80 and CD86) that may modulate immune recognition via both class I and class II pathways (Figure 3; Table 1). HLA class II Ag presentation is also partially regulated by another nonclassical class II molecule, HLA-DO, which is primarily expressed by B lymphocytes [124]. Overexpression of HLA-DO molecules correlates to inhibition of HLA-DM activity, resulting in accumulation of cell-surface CLIP [125]. Studies have shown that the EBV positive BL cell line Raji expresses much higher levels of HLA-DO when compared to two EBV negative BL cell lines, Ramos, and BJAB [125, 126]. Elevated levels of HLA-DO in BL cells correlate with much higher levels of cell-surface CLIP and may interfere with peptide binding to class II molecules. This provides one mechanism by which BL may escape immune detection via the HLA class II pathway of Ag presentation (Figure 3; Table 1).

Accumulating evidence suggests that endogenous Ags are also processed and presented by the class II molecules for stimulation of CD4+ T cells [127, 128]. Study has also demonstrated the proteasome and TAP-dependent pathway of HLA class II Ag presentation for two influenza epitopes [129]. Among the proteasome independent pathways, only macroautophagy has been observed to deliver endogenous substrates to HLA class II [127, 130]. Endogenous Ag can also be processed and delivered by macroautophagy to HLA class II for presentation to and activation of CD4+ T cells $[131,132]$. The involvement of macroautophagy in the presentation of EBNA1 to HLA class II may provide the means by which BL Ags could be presented to CD4+ T cells via the class II pathway.

While EBNA1 is not optimally processed or presented through the HLA class I pathway, healthy EBV seropositive individuals do produce EBNA1-specific CD4+ T cells. Studies have demonstrated that under certain conditions EBNA1 specific $T_{h}$ cells can recognize EBNA1 sensitized BL cells and mount an immune response, suggesting a role for HLA class II in the presentation of this Ag [133-135]. 
An EBNA1-specific CD4+ T-cell response was found to be required and sufficient to suppress tumor growth in a mouse model [136]. A possible role for $\mathrm{CD} 4+\mathrm{T}$ cells in mounting an EBNA1-targeted response is further evidenced by the fact that children with eBL demonstrate a loss of EBNA1-specific, IFN- $\gamma$-secreting T cells $[137,138]$.

Various groups have demonstrated the capacity of BLCL to efficiently present EBV-associated Ags to CD4+ T cells via HLA class II, but previously published results in our laboratory have revealed that BL cells are deficient in this ability $[33,139,140]$. We have demonstrated that BL express normal levels of HLA class II and the major components of the class II pathway, and that the expressed class II molecules were capable of binding peptide, but were incapable of activating CD4+ T cells (Figure 3 ). This was in contrast to B-LCL which functionally presented Ag to CD4+ $\mathrm{T}$ cells. The inability of $\mathrm{BL}$ to present $\mathrm{Ag}$ was overcome when the cells were incubated in a $\mathrm{pH} 5.5$ buffer, and elutions of BL-associated molecules prevented functional Ag presentation by B-LCL (unpublished data). These findings suggest that BLAIM may inhibit Ag presentation by HLA class II molecules (Figure 3). Abnormalities of HLA class II protein function in $\mathrm{BL}$ cells also impair cellular and humoral immune responses, suggesting that insights into $\mathrm{BL}$ pathogenesis and immune escape should be considered for devising better immunotherapeutics against BL.

\section{Conclusions}

BL is a highly aggressive non-Hodgkin's lymphoma, found primarily in equatorial Africa and Papua New Guinea, but also observed with lesser frequency in other parts of the world. Cases of BL may vary in EBV association and clinical manifestation, but virtually all show $c-m y c$ translocation to an Ig locus and resultant overexpression. Although the relative contributions of EBV, HIV, and malaria to the development of BL remain largely unclear, we discussed a host of factors that may influence BL pathogenesis. Similarly, the mechanisms by which BL may evade class II-restricted immune recognition were discussed. Future studies may focus on molecular events that alter $c-m y c$ expression and immune-mediated elimination of BL.

This paper suggests that the low immunogenicity of EBNA1 in EBV-positive BL is partially responsible for the poor $\mathrm{CD} 8+\mathrm{T}$ cell response, but this does not account for the diminished CD4+ T-cell response. Because CD8+ $\mathrm{T}$ cells are incapable of clearing BL cells, HLA class II Ag presentation and immune recognition of BL should receive more attention. Recent studies also indicate that alternative pathways for $\mathrm{Ag}$ processing may exist which would allow for HLA class II presentation of BL Ags through macroautophagy or cross-presentation. However, ongoing research in our laboratory strongly suggests the existence of a BL-associated inhibitory molecule(s) which blocks CD4+ T-cell activation in the context of HLA class II molecules. Current studies are being conducted to isolate and characterize this inhibitory molecule and determine its mode of action. Successful identification of this molecule would open doors for novel therapeutic treatments of BL as well as shed light on immune evasion strategies that may be used by other malignancies.

While currently used chemotherapy and chemoimmunotherapy treatment regimens for BL have achieved high survival rates in both adults and children, research in this area remains vitally important for several reasons: (a) adults show lower response rates than children, (b) adults are less tolerant of the treatment-associated toxicities and immunodeficiency, (c) HIV-associated BL patients suffer more severe mucositis and infections as a result of treatment, and (d) combination approaches are effective at improving survival rates, but the use of rituximab in HIV patients remains controversial. Factors that disrupt immune recognition demand further investigation for developing novel immunotherapies for better treatment and improved quality of life for the BL patients.

\section{Abbreviations}

BL: Burkitt lymphoma

NHL: Non-Hodgkin's lymphoma

HL: $\quad$ Hodgkin's lymphoma

DLBCL: Diffused large B cell lymphoma

B-LCL: B-lymphoblastoid cell line

EBV: $\quad$ Epstein-Barr virus

HIV: Human immunodeficiency virus

EBNA: Epstein-Barr virus nuclear antigen

LMP: Latent membrane protein

BLAIM: BL-associated inhibitory molecules

HLA: Human leukocyte antigen

CLIP: Class II-associated invariant chain peptide

CTL: $\quad$ Cytotoxic T lymphocyte.

\section{Acknowledgment}

This work was supported by Grants from the National Institutes of Health (CA129560 and CA129560-S1) to A. Haque.

\section{References}

[1] K. Booth, D. P. Burkitt, D. J. Bassett, R. A. Cooke, and J. Biddulph, "Burkitt lymphoma in Papua, New Guinea," British Journal of Cancer, vol. 21, no. 4, pp. 657-664, 1967.

[2] E. Klein and G. Klein, "Burkitt lymphoma," Seminars in Cancer Biology, vol. 19, no. 6, pp. 345-346, 2009.

[3] L. de Leval and R. P. Hasserjian, "Diffuse large B-cell lymphomas and burkitt lymphoma," Hematology/Oncology Clinics of North America, vol. 23, no. 4, pp. 791-827, 2009.

[4] G. W. Bornkamm, "Epstein-Barr virus and the pathogenesis of Burkitt's lymphoma: more questions than answers," International Journal of Cancer, vol. 124, no. 8, pp. 17451755, 2009.

[5] S. M. Mbulaiteye, R. J. Biggar, K. Bhatia, M. S. Linet, and S. S. Devesa, "Sporadic childhood Burkitt lymphoma incidence in the United States during 1992-2005," Pediatric Blood and Cancer, vol. 53, no. 3, pp. 366-370, 2009.

[6] C. Bellan, L. Stefano, D. F. Giulia, E. A. Rogena, and L. Lorenzo, "Burkitt lymphoma versus diffuse large B-cell 
lymphoma: a practical approach," Hematological Oncology, vol. 27, no. 4, pp. 182-185, 2009.

[7] A. D. Hislop, G. S. Taylor, D. Sauce, and A. B. Rickinson, "Cellular responses to viral infection in humans: lessons from Epstein-Barr virus," Annual Review of Immunology, vol. 25, pp. 587-617, 2007.

[8] C. Münz and A. Moormann, "Immune escape by EpsteinBarr virus associated malignancies," Seminars in Cancer Biology, vol. 18, no. 6, pp. 381-387, 2008.

[9] H. Williams and D. H. Crawford, "Epstein-Barr virus: the impact of scientific advances on clinical practice," Blood, vol. 107, no. 3, pp. 862-869, 2006.

[10] F. Pietersma, E. Piriou, and D. van Baarle, "Immune surveillance of EBV-infected B cells and the development of nonHodgkin lymphomas in immunocompromised patients," Leukemia and Lymphoma, vol. 49, no. 6, pp. 1028-1041, 2008.

[11] American Cancer Society, "Cancer Facts and Figures 2009," 2009.

[12] B. Fields, D. Knipe, and P. Howley, Fields Virology, vol. 2, Lippincott-Raven, 1996.

[13] K. Kawa, "Diagnosis and treatment of Epstein-Barr virusassociated natural killer cell lymphoproliferative disease," International Journal of Hematology, vol. 78, no. 1, pp. 24-31, 2003.

[14] A. L. Snow and O. M. Martinez, "Epstein-Barr virus: evasive maneuvers in the development of PTLD," American Journal of Transplantation, vol. 7, no. 2, pp. 271-277, 2007.

[15] A. T. Deyrup, "Epstein-Barr virus-associated epithelial and mesenchymal neoplasms," Human Pathology, vol. 39, no. 4, pp. 473-483, 2008.

[16] C. W. Tsang, X. Lin, N. H. Gudgeon et al., "CD4+ T-cell responses to Epstein-Barr virus nuclear antigen EBNA1 in Chinese populations are highly focused on novel C-terminal domain-derived epitopes," Journal of Virology, vol. 80, no. 16, pp. 8263-8266, 2006.

[17] T. A. Haigh, X. Lin, H. Jia et al., "EBV latent membrane proteins (LMPs) 1 and 2 as immunotherapeutic targets: LMP-specific CD4+ cytotoxic T cell recognition of EBVtransformed B cell lines," Journal of Immunology, vol. 180, no. 3, pp. 1643-1654, 2008.

[18] A. B. Rickinson and D. J. Moss, "Human cytotoxic T lymphocyte responses to Epstein-Barr virus infection," Annual Review of Immunology, vol. 15, pp. 405-431, 1997.

[19] G. Brady, G. J. MacArthur, and P. J. Farrell, "Epstein-Barr virus and Burkitt lymphoma," Postgraduate Medical Journal, vol. 84, no. 993, pp. 372-377, 2008.

[20] B. Vennstrom, D. Sheiness, J. Zabielski, and J. M. Bishop, "Isolation and characterization of c-myc, a cellular homolog of the oncogene (v-myc) of avian myelocytomatosis virus strain 29," Journal of Virology, vol. 42, no. 3, pp. 773-779, 1982.

[21] C. V. Dang, "c-Myc target genes involved in cell growth, apoptosis, and metabolism," Molecular and Cellular Biology, vol. 19, no. 1, pp. 1-11, 1999.

[22] C. E. Nesbit, J. M. Tersak, and E. V. Prochownik, "MYC oncogenes and human neoplastic disease," Oncogene, vol. 18, no. 19, pp. 3004-3016, 1999.

[23] C. V. Dang, K. A. O’Donnell, K. I. Zeller, T. Nguyen, R. C. Osthus, and F. Li, "The c-Myc target gene network," Seminars in Cancer Biology, vol. 16, no. 4, pp. 253-264, 2006.

[24] M. J. Allday, "How does Epstein-Barr virus (EBV) complement the activation of Myc in the pathogenesis of Burkitt's lymphoma?" Seminars in Cancer Biology, vol. 19, no. 6, pp. 366-376, 2009.
[25] B. Hoffman and D. A. Liebermann, "Apoptotic signaling by c-MYC," Oncogene, vol. 27, no. 50, pp. 6462-6472, 2008.

[26] V. S. Blinder, A. Chadburn, R. R. Furman, S. Mathew, and J. P. Leonard, "Review: improving outcomes for patients with Burkitt lymphoma and HIV," AIDS Patient Care and STDs, vol. 22, no. 3, pp. 175-187, 2008.

[27] D. H. Wright, "What is Burkitt's lymphoma and when is it endemic?" Blood, vol. 93, no. 2, p. 758, 1999.

[28] J. T. Yustein and C. V. Dang, "Biology and treatment of Burkitt's lymphoma," Current Opinion in Hematology, vol. 14, no. 4, pp. 375-381, 2007.

[29] S. M. Mbulaiteye, W. F. Anderson, K. Bhatia, P. S. Rosenberg, M. S. Linet, and S. S. Devesa, "Trimodal age-specific incidence patterns for Burkitt lymphoma in the United States, 1973-2005," International Journal of Cancer, vol. 126, no. 7, pp. 1732-1739, 2010.

[30] T. Onizuka, M. Moriyama, T. Yamochi et al., "BCL-6 gene product, a $92-$ to $98-\mathrm{kD}$ nuclear phosphoprotein, is highly expressed in germinal center B cells and their neoplastic counterparts," Blood, vol. 86, no. 1, pp. 28-37, 1995.

[31] C. J. Chapman, C. I. Mockridge, M. Rowe, A. B. Rickinson, and F. K. Stevenson, "Analysis of $\mathrm{V}(\mathrm{H})$ genes used by neoplastic B cells in endemic Burkitt's lymphoma shows somatic hypermutation and intraclonal heterogeneity," Blood, vol. 85, no. 8, pp. 2176-2181, 1995.

[32] C. J. Chapman, J. X. Zhou, C. Gregory, A. B. Rickinson, and F. K. Stevenson, "V(H) and $\mathrm{V}(\mathrm{L})$ gene analysis in sporadic Burkitt's lymphoma shows somatic hypermutation, intraclonal heterogeneity, and a role for antigen selection," Blood, vol. 88, no. 9, pp. 3562-3568, 1996.

[33] R. Küppers and R. Dalla-Favera, "Mechanisms of chromosomal translocations in B cell lymphomas," Oncogene, vol. 20, no. 40, pp. 5580-5594, 2001.

[34] R. Küppers, "B cells under influence: transformation of B cells by Epstein-Barr virus," Nature Reviews Immunology, vol. 3, no. 10, pp. 801-812, 2003.

[35] M. S. Staege, S. P. Lee, T. Frisan et al., "MYC overexpression imposes a nonimmunogenic phenotype on Epstein-Barr virus-infected B cells," Proceedings of the National Academy of Sciences of the United States of America, vol. 99, no. 7, pp. 4550-4555, 2002.

[36] M. L. Andersson, N. J. Stam, G. Klein, H. L. Ploegh, and M. G. Masucci, "Aberrant expression of HLA class-I antigens in Burkitt lymphoma cells," International Journal of Cancer, vol. 47, no. 4, pp. 544-550, 1991.

[37] S. Amria, C. Cameron, R. Stuart, and A. Haque, "Defects in HLA class II antigen presentation in B-cell lymphomas," Leukemia and Lymphoma, vol. 49, no. 2, pp. 353-355, 2008.

[38] N. Mutalima, E. Molyneux, H. Jaffe et al., "Associations between Burkitt lymphoma among children in Malawi and infection with HIV, EBV and malaria: results from a casecontrol study," PLoS ONE, vol. 3, no. 6, article e2505, 2008.

[39] N. Rasti, K. I. Falk, D. Donati et al., "Circulating EpsteinBarr virus in children living in malaria-endemic areas," Scandinavian Journal of Immunology, vol. 61, no. 5, pp. 461465, 2005.

[40] R. Njie, A. I. Bell, H. Jia et al., "The effects of acute malaria on Epstein-Barr virus (EBV) load and EBV-specific T cell immunity in Gambian children," Journal of Infectious Diseases, vol. 199, no. 1, pp. 31-38, 2009.

[41] E. Piriou, R. Kimmel, K. Chelimo et al., "Serological evidence for long-term Epstein-Barr virus reactivation in children living in a holoendemic malaria region of Kenya," Journal of Medical Virology, vol. 81, no. 6, pp. 1088-1093, 2009. 
[42] A. M. Moormann, K. Chelimo, P. O. Sumba, D. J. Tisch, R. Rochford, and J. W. Kazura, "Exposure to holoendemic malaria results in suppression of Epstein-Barr virus-specific T cell immunosurveillance in Kenyan children," Journal of Infectious Diseases, vol. 195, no. 6, pp. 799-808, 2007.

[43] A. Chene, D. Donati, J. Orem et al., "Endemic Burkitt's lymphoma as a polymicrobial disease. New insights on the interaction between Plasmodium falciparum and EpsteinBarr virus," Seminars in Cancer Biology, vol. 19, no. 6, pp. 411-420, 2009.

[44] K. Sebelin-Wulf, T. D. Nguyen, S. Oertel et al., "Quantitative analysis of EBV-specific CD4/CD8 T cell numbers, absolute CD4/CD8 $\mathrm{T}$ cell numbers and EBV load in solid organ transplant recipients with PLTD," Transplant Immunology, vol. 17, no. 3, pp. 203-210, 2007.

[45] I. T. Aldoss, D. D. Weisenburger, K. Fu et al., "Adult Burkitt lymphoma: advances in diagnosis and treatment," Oncology, vol. 22, no. 13, pp. 1508-1517, 2008.

[46] C. Patte, A. Auperin, M. Gerrard et al., "Results of the randomized international FAB/LMB96 trial for intermediate risk B-cell non-Hodgkin lymphoma in children and adolescents: it is possible to reduce treatment for the early responding patients," Blood, vol. 109, no. 7, pp. 2773-2780, 2007.

[47] I. Magrath, M. Adde, A. Shad et al., "Adults and children with small non-cleaved-cell lymphoma have a similar excellent outcome when treated with the same chemotherapy regimen," Journal of Clinical Oncology, vol. 14, no. 3, pp. 925-934, 1996.

[48] M. Diviné, P. Casassus, S. Koscielny et al., "Burkitt lymphoma in adults: a prospective study of 72 patients treated with an adapted pediatric LMB protocol," Annals of Oncology, vol. 16, no. 12, pp. 1928-1935, 2005.

[49] M. Di Nicola, C. Carlo-Stella, J. Mariotti et al., "High response rate and manageable toxicity with an intensive, short-term chemotherapy programme for Burkitt's lymphoma in adults," British Journal of Haematology, vol. 126, no. 6, pp. 815-820, 2004.

[50] M. Gerrard, M. S. Cairo, C. Weston et al., "Excellent survival following two courses of COPAD chemotherapy in children and adolescents with resected localized B-cell non-Hodgkin's lymphoma: results of the FAB/LMB 96 international study," British Journal of Haematology, vol. 141, no. 6, pp. 840-847, 2008.

[51] M. S. Cairo, M. Gerrard, R. Sposto et al., "Results of a randomized international study of high-risk central nervous system B non-Hodgkin lymphoma and B acute lymphoblastic leukemia in children and adolescents," Blood, vol. 109, no. 7, pp. 2736-2743, 2007.

[52] D. A. Thomas, S. Faderl, S. O’Brien et al., "Chemoimmunotherapy with hyper-CVAD plus rituximab for the treatment of adult Burkitt and Burkitt-type lymphoma or acute lymphoblastic leukemia," Cancer, vol. 106, no. 7, pp. 1569-1580, 2006.

[53] A. Oriol, J.-M. Ribera, J. Bergua et al., "High-dose chemotherapy and immunotherapy in adult Burkitt lymphoma: comparison of results in human immunodeficiency virus-infected and noninfected patients," Cancer, vol. 113, no. 1, pp. 117-125, 2008.

[54] J. Carnahan, R. Stein, Z. Qu et al., "Epratuzumab, a CD22targeting recombinant humanized antibody with a different mode of action from rituximab," Molecular Immunology, vol. 44, no. 6, pp. 1331-1341, 2007.
[55] M. A. Comito, Q. Sun, and K. G. Lucas, "Immunotherapy for Epstein-Barr virus-associated tumors," Leukemia and Lymphoma, vol. 45, no. 10, pp. 1981-1987, 2004.

[56] P. G. Spear and R. Longnecker, "Herpesvirus entry: an update," Journal of Virology, vol. 77, no. 19, pp. 10179-10185, 2003.

[57] M. P. McShane and R. Longnecker, "Cell-surface expression of a mutated Epstein-Barr virus glycoprotein B allows fusion independent of other viral proteins," Proceedings of the National Academy of Sciences of the United States of America, vol. 101, no. 50, pp. 17474-17479, 2004.

[58] Q. Li, M. K. Spriggs, S. Kovats et al., "Epstein-Barr virus uses HLA class II as a cofactor for infection of B lymphocytes," Journal of Virology, vol. 71, no. 6, pp. 4657-4662, 1997.

[59] K. M. Haan, S. Kyeong Lee, and R. Longnecker, "Different functional domains in the cytoplasmic tail of glycoprotein $\mathrm{B}$ are involved in Epstein-Barr virus-induced membrane fusion," Virology, vol. 290, no. 1, pp. 106-114, 2001.

[60] A. Szeles, K. I. Falk, S. Imreh, and G. Klein, "Visualization of alternative Epstein-Barr virus expression programs by fluorescent in situ hybridization at the cell level," Journal of Virology, vol. 73, no. 6, pp. 5064-5069, 1999.

[61] A. Carbone, A. Gloghini, and G. Dotti, "EBV-associated lymphoproliferative disorders: classification and treatment," Oncologist, vol. 13, no. 5, pp. 577-585, 2008.

[62] Y. Wu, S. Maruo, M. Yajima, T. Kanda, and K. Takada, "Epstein-Barr virus (EBV)-encoded RNA 2 (EBER2) but not EBER1 plays a critical role in EBV-induced B-cell growth transformation," Journal of Virology, vol. 81, no. 20, pp. 11236-11245, 2007.

[63] H. Kohlhof, F. Hampel, R. Hoffmann et al., "Notch1, Notch2, and Epstein-Barr virus-encoded nuclear antigen 2 signaling differentially affects proliferation and survival of EpsteinBarr virus-infected B cells," Blood, vol. 113, no. 22, pp. 55065515, 2009.

[64] B. Kempkes, D. Spitkovsky, P. Jansen-Durr et al., "B-cell proliferation and induction of early G1-regulating proteins by Epstein-Barr virus mutants conditional for EBNA2," EMBO Journal, vol. 14, no. 1, pp. 88-96, 1995.

[65] A. J. Sinclair, I. Palmero, G. Peters, and P. J. Farrell, "EBNA-2 and EBNA-LP cooperate to cause G0 to G1 transition during immortalization of resting human B lymphocytes by EpsteinBarr virus," EMBO Journal, vol. 13, no. 14, pp. 3321-3328, 1994.

[66] R. D. Palermo, H. M. Webb, A. Gunnell, and M. J. West, "Regulation of transcription by the Epstein-Barr virus nuclear antigen EBNA 2," Biochemical Society Transactions, vol. 36, no. 4, pp. 625-628, 2008.

[67] C. Kaiser, G. Laux, D. Eick, N. Jochner, G. W. Bornkamm, and B. Kempkes, "The proto-oncogene c-myc is a direct target gene of Epstein-Barr virus nuclear antigen 2," Journal of Virology, vol. 73, no. 5, pp. 4481-4484, 1999.

[68] S. Maier, G. Staffler, A. Hartmann et al., "Cellular target genes of Epstein-Barr virus nuclear antigen 2," Journal of Virology, vol. 80, no. 19, pp. 9761-9771, 2006.

[69] G. Moslalos, M. Birkenbach, R. Yalamanchili, T. VanArsdale, C. Ware, and E. Kieff, "The Epstein-Barr virus transforming protein LMP1 engages signaling proteins for the tumor necrosis factor receptor family," Cell, vol. 80 , no. 3, pp. 389399, 1995.

[70] D. A. Thorley-Lawson, "Epstein-Barr virus: exploiting the immune system," Nature Reviews Immunology, vol. 1, no. 1, pp. 75-82, 2001. 
[71] J. Rastelli, C. Hömig-Hölzel, J. Seagal et al., "LMP1 signaling can replace CD40 signaling in B cells in vivo and has unique features of inducing class-switch recombination to IgG1," Blood, vol. 111, no. 3, pp. 1448-1455, 2008.

[72] S. Maruo, Y. Wu, S. Ishikawa, T. Kanda, D. Iwakiri, and $\mathrm{K}$. Takada, "Epstein-Barr virus nuclear protein EBNA3C is required for cell cycle progression and growth maintanance of lymphoblastoid cells," Proceedings of the National Academy of Sciences of the United States of America, vol. 103, no. 51, pp. 19500-19505, 2006.

[73] A. Gerbitz, J. Mautner, C. Geltinger et al., "Deregulation of the proto-oncogene c-myc through $\mathrm{t}(8 ; 22)$ translocation in Burkitt's lymphoma," Oncogene, vol. 18, no. 9, pp. 17451753, 1999.

[74] Y. Dorsett, D. F. Robbiani, M. Jankovic, B. Reina-San-Martin, T. R. Eisenreich, and M. C. Nussenzweig, "A role for AID in chromosome translocations between c-myc and the IgH variable region," Journal of Experimental Medicine, vol. 204, no. 9, pp. 2225-2232, 2007.

[75] D. F. Robbiani, A. Bothmer, E. Callen et al., "AID is required for the chromosomal breaks in c-myc that lead to c-myc/IgH translocations," Cell, vol. 135, no. 6, pp. 1028-1038, 2008.

[76] C. Bellan, S. Lazzi, M. Hummel et al., "Immunoglobulin gene analysis reveals 2 distinct cells of origin for EBV-positive and EBV-negative Burkitt lymphomas," Blood, vol. 106, no. 3, pp. 1031-1036, 2005.

[77] B. Shiramizu, F. Barriga, J. Neequaye et al., "Patterns of chromosomal breakpoint locations in Burkitt's lymphoma: relevance to geography and Epstein-Barr virus association," Blood, vol. 77, no. 7, pp. 1516-1526, 1991.

[78] K. Busch, T. Keller, U. Fuchs et al., "Identification of two distinct MYC breakpoint clusters and their association with various IGH breakpoint regions in the $\mathrm{t}(8 ; 14)$ translocations in sporadic Burkitt-lymphoma," Leukemia, vol. 21, no. 8, pp. 1739-1751, 2007.

[79] J. D. Gordan, C. B. Thompson, and M. C. Simon, "HIF and cMyc: sibling rivals for control of cancer cell metabolism and proliferation," Cancer Cell, vol. 12, no. 2, pp. 108-113, 2007.

[80] I. Magrath, "The pathogenesis of Burkitt's lymphoma," Advances in Cancer Research, vol. 55, pp. 133-270, 1990.

[81] G. Kennedy, J. Komano, and B. Sugden, "Epstein-Barr virus provides a survival factor to Burkitt's lymphomas," Proceedings of the National Academy of Sciences of the United States of America, vol. 100, no. 24, pp. 14269-14274, 2003.

[82] J. Shi, J. S. Stover, L. R. Whitby, P. K. Vogt, and D. L. Boger, "Small molecule inhibitors of Myc/Max dimerization and Myc-induced cell transformation," Bioorganic and Medicinal Chemistry Letters, vol. 19, no. 21, pp. 6038-6041, 2009.

[83] E. Leucci, M. Cocco, A. Onnis et al., "MYC translocationnegative classical Burkitt lymphoma cases: an alternative pathogenetic mechanism involving miRNA deregulation," Journal of Pathology, vol. 216, no. 4, pp. 440-450, 2008.

[84] A. Sharipo, M. Imreh, A. Leonchiks, S. Imreh, and M. G. Masucci, "A minimal glycine-alanine repeat prevents the interaction of ubiquitinated $\mathrm{I} \kappa \mathrm{B} \alpha$ with the proteasome: a new mechanism for selective inhibition of proteolysis," Nature Medicine, vol. 4, no. 8, pp. 939-944, 1998.

[85] Y. Yin, B. Manoury, and R. Fåhraeus, "Self-inhibition of synthesis and antigen presentation by Epstein-Barr virusencoded EBNA1," Science, vol. 301, no. 5638, pp. 1371-1374, 2003.

[86] M. Schlee, M. Hölzel, S. Bernard et al., "c-MYC activation impairs the NF- $\kappa \mathrm{B}$ and the interferon response: implications for the pathogenesis of Burkitt's lymphoma," International Journal of Cancer, vol. 120, no. 7, pp. 1387-1395, 2007.

[87] M. Billaud, F. Rousset, A. Calender et al., "Low expression of lymphocyte function-associated antigen (LFA)-1 and LFA-3 adhesion molecules is a common trait in Burkitt's lymphoma associated with and not associated with Epstein-Barr virus," Blood, vol. 75, no. 9, pp. 1827-1833, 1990.

[88] T. Frisan, V. Levitsky, A. Polack, and M. G. Masucci, "Phenotype-dependent differences in proteasome subunit composition and cleavage specificity in B cell lines," Journal of Immunology, vol. 160, no. 7, pp. 3281-3289, 1998.

[89] C. D. Gregory, R. J. Murray, C. F. Edwards, and A. B. Rickinson, "Downregulation of cell adhesion molecules LFA-3 and ICAM-1 in Epstein-Barr virus-positive Burkitt's lymphoma underlies tumor cell escape from virus-specific $\mathrm{T}$ cell surveillance," Journal of Experimental Medicine, vol. 167, no. 6, pp. 1811-1824, 1988.

[90] K. Klapproth, S. Sander, D. Marinkovic, B. Baumann, and T. Wirth, "The IKK2/NF- $\kappa$ B pathway suppresses MYC-induced lymphomagenesis," Blood, vol. 114, no. 12, pp. 2448-2458, 2009.

[91] S. P. Lee, J. M. Brooks, H. Al-Jarrah et al., "CD8 T cell recognition of endogenously expressed Epstein-Barr virus nuclear antigen 1," Journal of Experimental Medicine, vol. 199, no. 10, pp. 1409-1420, 2004.

[92] J. Tellam, G. Connolly, K. J. Green et al., "Endogenous presentation of CD8+ $\mathrm{T}$ cell epitopes from Epstein-Barr virus-encoded nuclear antigen 1," Journal of Experimental Medicine, vol. 199, no. 10, pp. 1421-1431, 2004.

[93] S. Nikiforow, K. Bottomly, G. Miller, and C. Münz, "Cytolytic CD4+-T-cell clones reactive to EBNA1 inhibit Epstein-Barr virus-induced B-cell proliferation," Journal of Virology, vol. 77, no. 22, pp. 12088-12104, 2003.

[94] K. N. Heller, J. Upshaw, B. Seyoum, H. Zebroski, and C. Münz, "Distinct memory CD4+ T-cell subsets mediate immune recognition of Epstein Barr virus nuclear antigen 1 in healthy virus carriers," Blood, vol. 109, no. 3, pp. 11381146, 2007.

[95] C. S. Leung, T. A. Haigh, L. K. Mackay, A. B. Rickinson, and G. S. Taylor, "Nuclear location of an endogenously expressed antigen, EBNA1, restricts access to macroautophagy and the range of CD4 epitope display," Proceedings of the National Academy of Sciences of the United States of America, vol. 107, no. 5, pp. 2165-2170, 2010.

[96] C. S. Leung and G. S. Taylor, "Nuclear shelter: the influence of subcellular location on the processing of antigens by macroautophagy," Autophagy, vol. 6, no. 4, pp. 560-561, 2010.

[97] G. Kelly, A. Bell, and A. Rickinson, "Epstein-Barr virusassociated Burkitt lymphomagenesis selects for downregulation of the nuclear antigen EBNA2," Nature Medicine, vol. 8, no. 10, pp. 1098-1104, 2002.

[98] S. S. Dave, K. Fu, G. W. Wright et al., "Molecular diagnosis of Burkitt's lymphoma," New England Journal of Medicine, vol. 354, no. 23, pp. 2431-2442, 2006.

[99] M. Hummel, S. Bentink, H. Berger et al., "A biologic definition of Burkitt's lymphoma from transcriptional and genomic profiling," New England Journal of Medicine, vol. 354, no. 23, pp. 2419-2430, 2006.

[100] K. L. Csencsits and D. K. Bishop, "Contrasting alloreactive CD4+ and CD8+ T cells: there's more to it than MHC restriction," American Journal of Transplantation, vol. 3, no. 2, pp. 107-115, 2003. 
[101] W. Held, A. Chalifour, and J. D. Coudert, "Regulation of natural killer cell function: a role for the NK cell's own MHC class I molecules," Medical Microbiology and Immunology, vol. 194, no. 4, pp. 169-174, 2005.

[102] I. A. York and K. L. Rock, "Antigen processing and presentation by the class I major histocompatibility complex," Annual Review of Immunology, vol. 14, pp. 369-396, 1996.

[103] P. M. Day, J. W. Yewdell, A. Porgador, R. N. Germain, and J. R. Bennink, "Direct delivery of exogenous MHC class I molecule-binding oligopeptides to the endoplasmic reticulum of viable cells," Proceedings of the National Academy of Sciences of the United States of America, vol. 94, no. 15, pp. 8064-8069, 1997.

[104] X.-L. Huang, Z. Fan, B. A. Colleton et al., "Processing and presentation of exogenous HLA class I peptides by dendritic cells from human immunodeficiency virus type 1-infected persons," Journal of Virology, vol. 79, no. 5, pp. 3052-3062, 2005.

[105] R. Khanna, S. R. Burrows, P. M. Steigerwald-Mullen, D. J. Moss, M. G. Kurilla, and L. Cooper, "Targeting Epstein-Barr virus nuclear antigen 1 (EBNA1) through the class II pathway restores immune recognition by EBNA1-specific cytotoxic T lymphocytes: evidence for HLA-DM-independent processing," International Immunology, vol. 9, no. 10, pp. 1537-1543, 1997.

[106] M. G. Masucci, S. Torsteinsdottir, and J. Colombani, "Downregulation of class I HLA antigens and of the EpsteinBarr virus-encoded latent membrane protein in Burkitt lymphoma lines," Proceedings of the National Academy of Sciences of the United States of America, vol. 84, no. 13, pp. 4567-4571, 1987.

[107] R. Gavioli, P. O. De Campos-Lima, M. G. Kurilla, E. Kieff, G. Klein, and M. G. Masucci, "Recognition of the EpsteinBarr virus-encoded nuclear antigens EBNA- 4 and EBNA- 6 by HLA-A11-restricted cytotoxic T lymphocytes: implications for down- regulation of HLA-A11 in Burkitt lymphoma," Proceedings of the National Academy of Sciences of the United States of America, vol. 89, no. 13, pp. 5862-5866, 1992.

[108] T. Frisan, Q.-J. Zhang, J. Levitskaya, M. Coram, M. G. Kurilla, and M. G. Masucci, "Defective presentation of MHC class I-restricted cytotoxic T-cell epitopes in Burkitt's lymphoma cells," International Journal of Cancer, vol. 68, no. 2, pp. 251258, 1996.

[109] W. Jilg, R. Voltz, C. Markert-Hahn, H. Mairhofer, I. Munz, and $\mathrm{H}$. Wolf, "Expression of class I major histocompatibility complex antigens in Epstein-Barr virus-carrying lymphoblastoid cell lines and Burkitt lymphoma cells," Cancer Research, vol. 51, no. 1, pp. 27-32, 1991.

[110] N. Rocha and J. Neefjes, "MHC class II molecules on the move for successful antigen presentation," EMBO Journal, vol. 27 , no. 1 , pp. $1-5,2008$.

[111] A. Haque and J. S. Blum, "New insights in antigen processing and epitope selection: development of novel immunotherapeutic stragies for cancer, autoimmunity and infectious diseases," Journal of Biological Regulators and Homeostatic Agents, vol. 19, no. 3-4, pp. 93-104, 2005.

[112] L. J. Stern, I. Potolicchio, and L. Santambrogio, "MHC class II compartment subtypes: structure and function," Current Opinion in Immunology, vol. 18, no. 1, pp. 64-69, 2006.

[113] O. J. B. Landsverk, O. Bakke, and T. F. Gregers, "MHC II and the endocytic pathway: regulation by invariant chain," Scandinavian Journal of Immunology, vol. 70, no. 3, pp. 184193, 2009.
[114] X. Chen and P. E. Jensen, "MHC class II antigen presentation and immunological abnormalities due to deficiency of MHC class II and its associated genes," Experimental and Molecular Pathology, vol. 85, no. 1, pp. 40-44, 2008.

[115] M. Matloubian, R. J. Concepcion, and R. Ahmed, "CD4+ T cells are required to sustain CD8+ cytotoxic T-cell responses during chronic viral infection," Journal of Virology, vol. 68, no. 12, pp. 8056-8063, 1994.

[116] J.-Q. Mi, O. Manches, J. Wang et al., "Development of autologous cytotoxic CD4+ T clones in a human model of B-cell non-Hodgkin follicular lymphoma," British Journal of Haematology, vol. 135, no. 3, pp. 324-335, 2006.

[117] A. Rudensky and C. Beers, "Lysosomal cysteine proteases and antigen presentation," Ernst Schering Research Foundation workshop., no. 56, pp. 81-95, 2006.

[118] M. Maric, B. Arunachalam, U. T. Phan et al., "Defective antigen processing in GILT-free mice," Science, vol. 294, no. 5545, pp. 1361-1365, 2001.

[119] M. A. Haque, P. Li, S. K. Jackson et al., "Absence of $\gamma$ interferon-inducible lysosomal thiol reductase in melanomas disrupts $\mathrm{T}$ cell recognition of select immunodominant epitopes," Journal of Experimental Medicine, vol. 195, no. 10, pp. 1267-1277, 2002.

[120] O. G. Goldstein, L. M. Hajiaghamohseni, S. Amria, K. Sundaram, S. V. Reddy, and A. Haque, "Gamma-IFN-induciblelysosomal thiol reductase modulates acidic proteases and HLA class II antigen processing in melanoma," Cancer Immunology, Immunotherapy, vol. 57, no. 10, pp. 1461-1470, 2008.

[121] K. T. Hastings, R. L. Lackman, and P. Cresswell, "Functional requirements for the lysosomal thiol reductase GILT in MHC class II-restricted antigen processing," Journal of Immunology, vol. 177, no. 12, pp. 8569-8577, 2006.

[122] L. K. Denzin, J. L. Fallas, M. Prendes, and W. Yi, "Right place, right time, right peptide: DO keeps DM focused," Immunological Reviews, vol. 207, pp. 279-292, 2005.

[123] S. Sadegh-Nasseri, M. Chen, K. Narayan, and M. Bouvier, "The convergent roles of tapasin and HLA-DM in antigen presentation," Trends in Immunology, vol. 29, no. 3, pp. 141147, 2008.

[124] X. Chen and P. E. Jensen, "The expression of HLA-DO (H2O) in B lymphocytes," Immunologic Research, vol. 29, no. 1-3, pp. 19-28, 2004.

[125] H. Khalil, F. Deshaies, A. Bellemare-Pelletier et al., "Class II transactivator-induced expression of HLA-DO $\beta$ in Hela cells," Tissue Antigens, vol. 60, no. 5, pp. 372-382, 2002.

[126] C. Roucard, C. Thomas, M.-A. Pasquier et al., "In vivo and in vitro modulation of HLA-DM and HLA-DO is induced by B lymphocyte activation," Journal of Immunology, vol. 167, no. 12, pp. 6849-6858, 2001.

[127] R. Busch, C. H. Rinderknecht, S. Roh et al., "Achieving stability through editing and chaperoning: regulation of MHC class II peptide binding and expression," Immunological Reviews, vol. 207, pp. 242-260, 2005.

[128] J. Nedjic, M. Aichinger, N. Mizushima, and L. Klein, "Macroautophagy, endogenous MHC II loading and T cell selection: the benefits of breaking the rules," Current Opinion in Immunology, vol. 21, no. 1, pp. 92-97, 2009.

[129] M. K. Tewari, G. Sinnathamby, D. Rajagopal, and L. C. Eisenlohr, "A cytosolic pathway for MHC class II-restricted antigen processing that is proteasome and TAP dependent," Nature Immunology, vol. 6, no. 3, pp. 287-294, 2005. 
[130] V. L. Crotzer and J. S. Blum, "Autophagy and its role in MHCmediated antigen presentation," Journal of Immunology, vol. 182, no. 6, pp. 3335-3341, 2009.

[131] J. D. Lünemann and C. Münz, "Autophagy in CD4+ T-cell immunity and tolerance," Cell Death and Differentiation, vol. 16, no. 1, pp. 79-86, 2009.

[132] C. Paludan, D. Schmid, M. Landthaler et al., "Endogenous MHC class II processing of a viral nuclear antigen after autophagy," Science, vol. 307, no. 5709, pp. 593-596, 2005.

[133] R. Khanna, S. R. Burrows, S. A. Thomson et al., "Class I processing-defective Burkitt's lymphoma cells are recognized efficiently by CD4+ EBV-specific CTLs," Journal of Immunology, vol. 158, no. 8, pp. 3619-3625, 1997.

[134] C. Paludan, K. Bickham, S. Nikiforow et al., "Epstein-Barr nuclear antigen 1-specific CD4+ Th1 cells kill Burkitt's lymphoma cells," Journal of Immunology, vol. 169, no. 3, pp. 1593-1603, 2002.

[135] K. S. Voo, T. Fu, H. E. Heslop, M. K. Brenner, C. M. Rooney, and R.-F. Wang, "Identification of HLA-DP3-restricted peptides from EBNA1 recognized by CD4+ T cells," Cancer Research, vol. 62, no. 24, pp. 7195-7199, 2002.

[136] T. Fu, S. V. Kui, and R.-F. Wang, "Critical role of EBNA1specific $\mathrm{CD} 4+\mathrm{T}$ colls in the control of mouse Burkitt lymphoma in vivo," Journal of Clinical Investigation, vol. 114, no. 4, pp. 542-550, 2004.

[137] A. M. Moormann, K. N. Heller, K. Chelimo et al., "Children with endemic Burkitt lymphoma are deficient in EBNAlspecific IFN- $\gamma$ T cell responses," International Journal of Cancer, vol. 124, no. 7, pp. 1721-1726, 2009.

[138] A. M. Moormann and J. S. Lozada, "Burkitt lymphoma in uganda: 50 years of ongoing discovery," Pediatric Blood and Cancer, vol. 52, no. 4, pp. 433-434, 2009.

[139] H. M. Long, T. A. Haigh, N. H. Gudgeon et al., "CD4+ T-cell responses to epstein-barr virus (EBV) latent-cycle antigens and the recognition of EBV-transformed lymphoblastoid cell lines," Journal of Virology, vol. 79, no. 8, pp. 4896-4907, 2005.

[140] H. M. Long, J. Zuo, A. M. Leese et al., "CD4+ T-cell clones recognizing human lymphoma-associated antigens: generation by in vitro stimulation with autologous EpsteinBarr virus-transformed B cells," Blood, vol. 114, no. 4, pp. 807-815, 2009. 


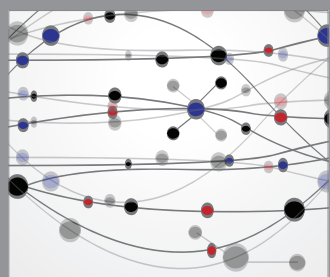

The Scientific World Journal
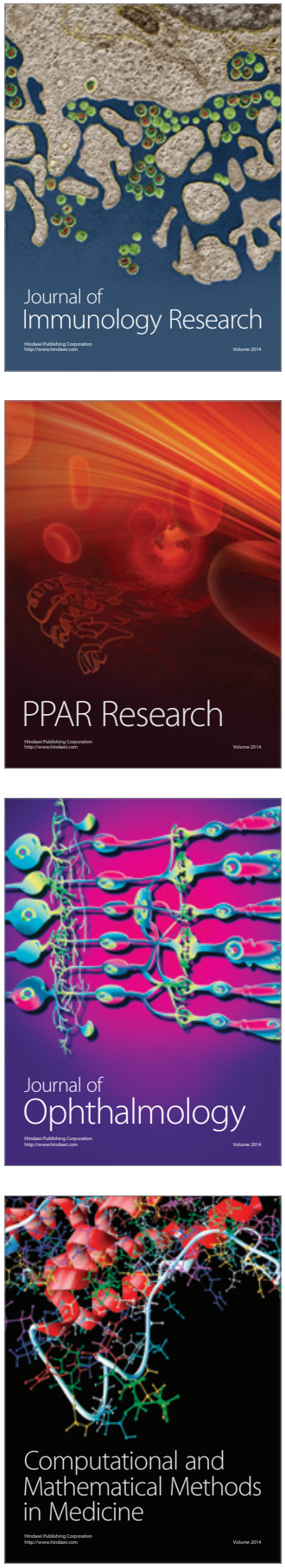

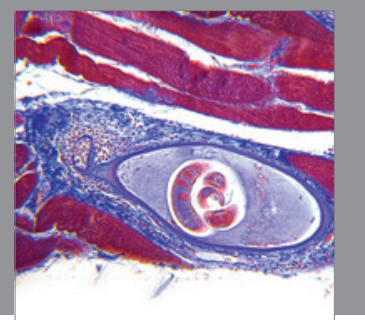

Gastroenterology

Research and Practice
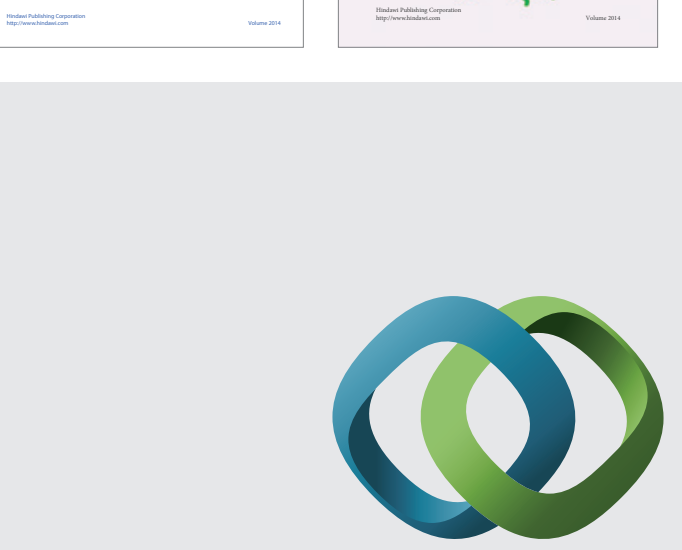

\section{Hindawi}

Submit your manuscripts at

http://www.hindawi.com
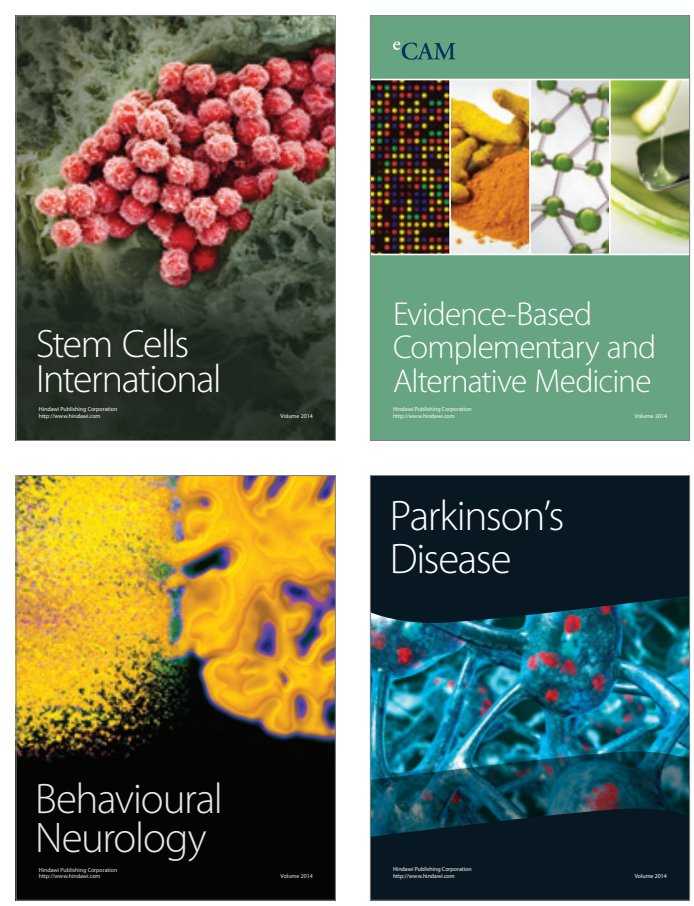

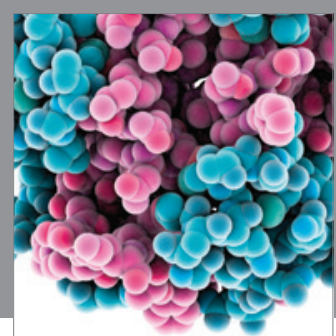

Journal of
Diabetes Research

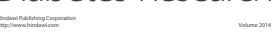

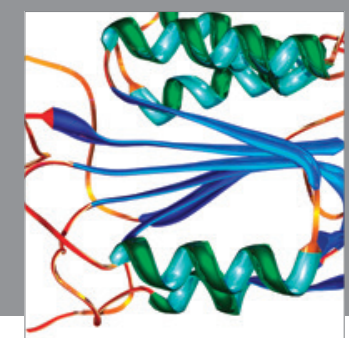

Disease Markers
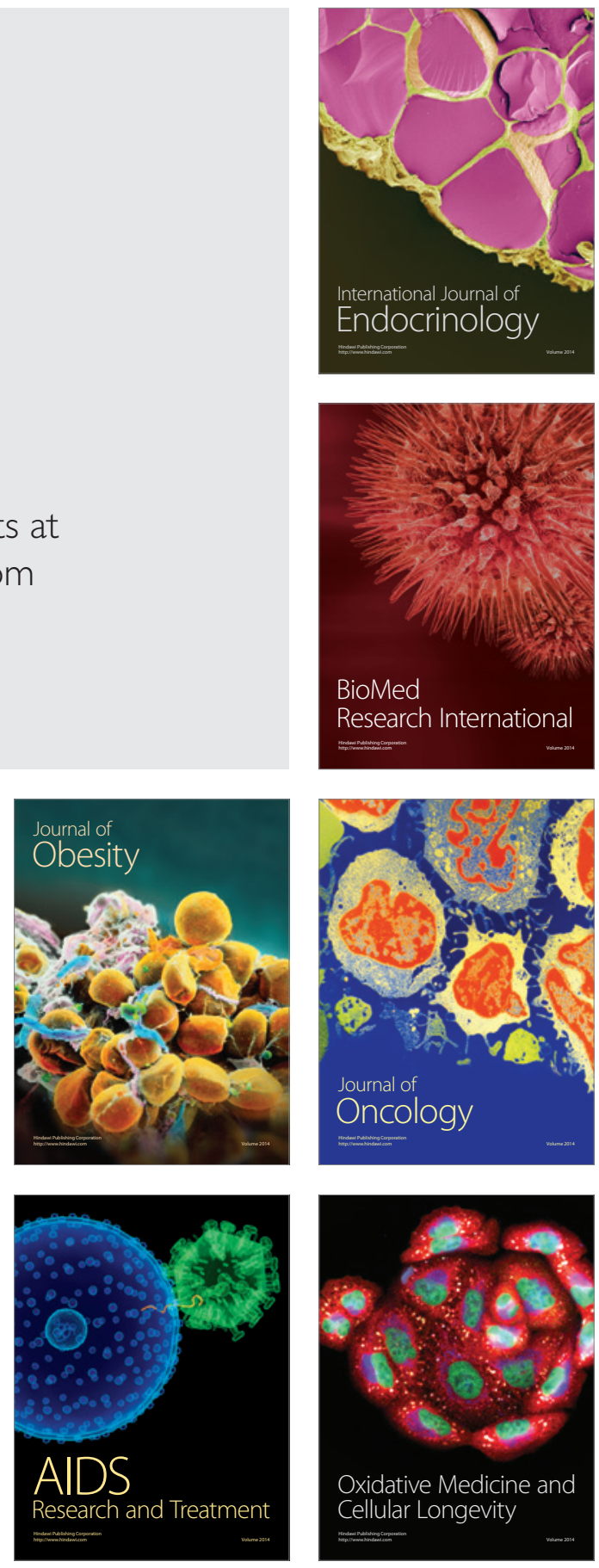